\title{
SYNTHESIS, ANTIMICROBIAL EVALUATION, DENSITY FUNCTIONAL THEORY, AND DOCKING STUDIES OF SOME NEW 2-MERCAPTO PYRIMIDINE SCHIFF BASES
}

\author{
SAHAR B. AL-JUBOORI ${ }^{1}$, AMMAR A. RAZZAK MAHMOOD ${ }^{2 *}$
}

${ }^{1}$ Department of Pharmacy, College of Al-Rafidain University, Baghdad, Iraq. ${ }^{2}$ Department of Pharmaceutical Chemistry, College of Pharmacy, University of Baghdad, Bab-Al-Mouadam, 10001, Baghdad, Iraq. Email: kubbaammar1963@gmail.com

Received: 21 November 2018, Revised and Accepted: 05 January 2019

\section{ABSTRACT}

Objective: Pyrimidine derivatives are reported to possess antibacterial, antifungal, anticancer, and anticonvulsant activities. Encouraged by this remarks, we decided to synthesize novel compounds of new 2-macraptopyrimidine linked to Schiffs' bases.

Methods: The present work involves the synthesis of new 2-mercaptopyrimidine linked to Schiffs' bases. The starting, 2-mercaptopyrimidine, compound (1) reacted with thiourea to afford the corresponding 1-(pyrimidin-2-yl) thiourea (2). Then compound (2) was used as the key intermediate to prepare the -1-(2-hydroxy benzylidene)-3-(pyrimidin-2-yl) thiourea (3), and (1-benzylidine)-3-(pyrimidin-2-yl) thiourea (4), through the reaction with 2-hydroxybenzaldehyde, and benzaldehyde, respectively.

Results: All the synthesized compounds were characterized by Fourier-transform infrared and ${ }^{1} \mathrm{H}$-nuclear magnetic resonance spectroscopy. The synthesized derivatives were screened for their in vitro, antibacterial activity against two Gram-positive bacteria: Bacillus subtilis and Staphylococcus aureus and four Gram-negative bacteria: Klebsiella pneumoniae, Escherichia coli, and Salmonella typhi, and the results showed that most of them have good antibacterial activity. While their antifungal activity against four fungi species (Aspergillus fumigates, Aspergillus niger, Aspergillus terrus and Rhizopus) revealed that compounds (2-4) displayed the most potent antifungal activity. Density functional theory (DFT) calculations for the synthesized 2-mercapto pyrimidine derivatives were conducted, using a molecular structure with optimized geometry. Highest occupied molecular orbital/lowest unoccupied molecular orbital energies and structures are demonstrated.

Conclusion: The antimicrobial activity indicates that compounds (3) and (4) are the most active than the compounds (1) and (2). Molecular docking revealed that compounds (3) and (4), with bulky phenyl groups are essential to blocking the active centers of glucose -6-phosphate synthase in the bacteria and fungi.

Keywords: Antimicrobial, Density functional theory, 2-Mercaptopyrimidine, Schiff bases, Glucose-6-phosphate synthase.

(c) 2019 The Authors. Published by Innovare Academic Sciences Pvt Ltd. This is an open access article under the CC BY license (http://creativecommons. org/licenses/by/4. 0/) DOI: http://dx.doi.org/10.22159/ajpcr.2019.v12i2.30858

\section{INTRODUCTION}

Pyrimidines are essential six-membered heterocyclic compounds containing two nitrogen atoms. Pyrimidines present in the form of nucleic acids and vitamins. It has basic properties. It has been found to be associated with different biological activities. Further work led to the development of antimalarial drugs such as pyrimethamine and trimethoprim. Additional chemical modifications have afforded interesting pyrimidine derivatives like oxythiamine. The variety of compounds having a pyrimidine nucleus exhibit wide range of biological activities such as antiviral [1], antileishmanial [2], antimalarial [3], antihistaminic [4], anti-inflammatory [5], and antitubercular [6] activities. Many essential drugs and agrochemicals containing pyrimidines and their derivatives possess numerous and remarkable biological activities such as antimicrobial [7] and antitumor [8]. Pyrimidine derivatives have been reported to exhibit various pharmacological activities such as antiepileptic, antihypertensive Minoxidil, and potent phosphodiesterase inhibitors $[9,10]$. Schiff bases are condensation products of primary amines with carbonyl compounds. The main structural feature of these compounds is the azomethine group with a general formula RHC=N-R1, where R and R1 are alkyls, aryl, cycloalkyl or heterocyclic groups which may be variously substituted [11].

The chemical formula of Schiff bases contains N-donor atom has been widely investigated and has acquired great attention due to the azomethine $\mathrm{C}=\mathrm{N}$ bond essential for biological activity, nowadays, cases of microbial resistance pose a big deal to the scientific community and have become a threat to human life worldwide. Moreover, invasive microbial infections caused by multidrug-resistant Gram- positive bacteria and microbes are difficult to diagnose. Therefore, the development of new, effective, and safe antimicrobial agents is urgently required, to overcome the problems of microbial resistance [12]

The goal of this work is to synthesize of some new Schiff bases, derived from 2-mercapto pyrimidine (1), by reacting it, with thiourea, using acetic acid medium, then, the produced thiourea derivative will be treated with two different aromatic aldehydes to afford Schiff bases. The titled compounds (1-4) would be screened, in vitro, for their antimicrobial activities.

Furthermore, conducting (density functional theory [DFT]) and docking studies to calculate some important physical parameters, and to observe the binding sites of the functional groups of the synthesized derivatives (2-4), with the enzyme glucose-6-phosphate synthase, respectively.

\section{MATERIALS AND METHODS}

Chemicals used during the synthesis, supplied by Sigma-Aldrich. Solvents were dried and distilled before use. Completion of reactions and the purity of compounds were ascertained by thin-layer chromatography (TLC), using Silica gel $\mathrm{GF}_{254}$ (type 60) pre-coated aluminum sheets, Merck (Germany). Melting points were measured using Kofler hotstage apparatus and are uncorrected. IR (KBr) spectra $\left(\mathrm{v}, \mathrm{cm}^{-1}\right)$ were recorded using Thermo Scientific ${ }^{\mathrm{TM}}$ Nicolet $^{\mathrm{TM}}{ }^{\mathrm{M}} \mathrm{S}^{\mathrm{TM}} 10$ Fourier-transform infrared spectrophotometer in College of Education Ibn al-HaithamIraq. Nuclear magnetic resonance $\left({ }^{1} \mathrm{H}-\mathrm{NMR}\right)$ spectra were recorded on Bruker FT-NMR spectrometer 300, at AL-Bayt University-Amman/ Jordan, using deuterated dimethyl sulfoxide (DMSO- ${ }_{-16}$ ) as a solvent, 
and tetramethylsilane as an internal standard. A computational study was performed for the prepared compounds using Chemical Bio Office 2016, version 16, DFT study with 3_21G* basis, while molecular docking study was run using molecular operation environment program, 2105.

\section{Synthesis of 1-(pyrimidin-2-yl) thiourea (2)}

A mixture of pyrimidine-2-thiol (1) $(0.01 \mathrm{~mol}, 1.12 \mathrm{~g})$ and thiourea $(0.01$ $\mathrm{mol}, 1.82 \mathrm{~g}$ ) was dissolved in absolute ethanol $(30 \mathrm{ml}) .2 \mathrm{ml}$ of acetic acid was added, and the reaction mixture was refluxed on a water bath for about $6 \mathrm{~h}$. The solid separated after concentration and cooling was recrystallized from themethanol to give (2). IR $(\mathrm{KBr}),\left(\mathrm{v}, \mathrm{cm}^{-1}\right): 3366$, and 3287 prim $\left(\mathrm{NH}_{2}\right)$ str; $3161(\mathrm{~N}-\mathrm{H})$ str; $3053 \mathrm{Ar}(\mathrm{C}-\mathrm{H})$ str; $1633(\mathrm{C}=\mathrm{N})$ str; $1533(\mathrm{~N}-\mathrm{H})$ bend; 1213 (C=S) str; $1473 \mathrm{Ar}(\mathrm{C}=\mathrm{C})$ str; 1198 (C-N) str.; 1038 and 906 in plane and out of plane $\operatorname{Ar}(\mathrm{C}-\mathrm{H})$ bend; 727 out of plane $\operatorname{Ar}(\mathrm{C}=\mathrm{C})$ bend; 669 (C- Br) str; 636 (C-S) str. ${ }^{1} \mathrm{HNMR}(300 \mathrm{MHz}$, DMSO$\delta=$ ppm) : $8.59\left(2 \mathrm{H}, \mathrm{s}, \mathrm{NH}_{2}-(\mathrm{C}=\mathrm{S}) ; 7.39(1 \mathrm{H}, \mathrm{s}, \mathrm{NH}(\mathrm{C}=\mathrm{S}) ; 7.93(2 \mathrm{H}, \mathrm{d}, 2 \mathrm{Ar}-\right.$ $\mathrm{H}) ; 7.73(1 \mathrm{H}, \mathrm{t}, \mathrm{Ar}-\mathrm{H})$.

Synthesis of 1-(2-hydroxybenzylidene)-3-(pyrimidin-2-yl)thiourea (3) Compound (2) $(0.01 \mathrm{~mol}, 1.38 \mathrm{~g})$ was added with continuous stirring to a solution of 2-hydroxybenzaldehyde ( $0.01 \mathrm{~mol}, 1.22 \mathrm{~g})$, and five drops of glacial acetic acid in $(40 \mathrm{ml})$ absolute ethanol. The mixture was refluxed for $6 \mathrm{~h}$, and the reaction was monitored by TLC, the orange colored precipitate was formed, and collected by filtration, washed with ether, then dried and recrystallized from methanol. IR (KBr), $\left(\mathrm{v}, \mathrm{cm}^{-1}\right): 3399(\mathrm{OH})$ str. $3166(\mathrm{NH})$ str; 3113 Ar (C-H) str; 1608 (C=N) str; $1568(\mathrm{~N}-\mathrm{H})$ bend; 1217 (C=S) str; 1489 $\operatorname{Ar}(\mathrm{C}=\mathrm{C})$ str; $1186(\mathrm{C}-\mathrm{N})$ str; 1049 and 982 in plane and out of plane $\mathrm{Ar}(\mathrm{C}-\mathrm{H})$ bend; 793 out of plane $\mathrm{Ar}(\mathrm{C}=\mathrm{C})$ bend; $744 \mathrm{~cm}^{-1}$ (C-S) str. ${ }^{1} \mathrm{HNMR}(300 \mathrm{MHz}$, DMSO- $\left._{d 6^{\prime}} \delta=\mathrm{ppm}\right): 12.11(1 \mathrm{H}, \mathrm{s}, \mathrm{OH}-\mathrm{Ar}), 8.58(1 \mathrm{H}, \mathrm{s}, \mathrm{NH}-(\mathrm{C}=\mathrm{S}), 6.93(1 \mathrm{H}, \mathrm{s}$, $(\mathrm{N}=\mathrm{CH}) ; 7.07-8.12(7 \mathrm{H}, \mathrm{m}, \mathrm{Ar}-\mathrm{H})$.

\section{Synthesis of (1-benzylidene) 3- (pyrimidin -2-yl) thiourea (4)}

Compound (2) ( $0.01 \mathrm{~mol}, 1.38 \mathrm{~g}$ ) was added with continuous stirring to a solution of benzaldehyde, $(0.01 \mathrm{~mol}, 1.06 \mathrm{~g})$ and five drops of glacial acetic acid, in $40 \mathrm{ml}$ absolute ethanol. The mixture was refluxed for $6 \mathrm{~h}$, and the reaction was monitored by TLC, the orange colored precipitate was formed and collected by filtration, washed with ether, then dried and recrystallized from methanol. IR ( $\mathrm{KBr}),\left(\mathrm{U}, \mathrm{cm}^{-1}\right): 3153(\mathrm{NH})$ str; $3077 \mathrm{Ar}(\mathrm{C}-\mathrm{H})$ str; 1638 $(\mathrm{C}=\mathrm{N})$ str; $1586(\mathrm{~N}-\mathrm{H})$ bend; $1431 \mathrm{Ar}(\mathrm{C}=\mathrm{C})$ str; $1186(\mathrm{C}-\mathrm{N})$ str; 1149 in plane $\mathrm{Ar}(\mathrm{C}-\mathrm{H})$ bend; 1237 (C=S) str. ${ }^{1} \mathrm{HNMR}\left(300 \mathrm{MHz}\right.$, DMSO- $\left.{ }_{d \sigma} \delta=\mathrm{ppm}\right)$ : $8.26(1 \mathrm{H}, \mathrm{s}, \mathrm{NH}(\mathrm{C}=\mathrm{S}), 6.68(1 \mathrm{H}, \mathrm{s}, \mathrm{N}=\mathrm{CH}) ; 6.77-8.18(8 \mathrm{H}, \mathrm{m}, \mathrm{Ar}-\mathrm{H})$.
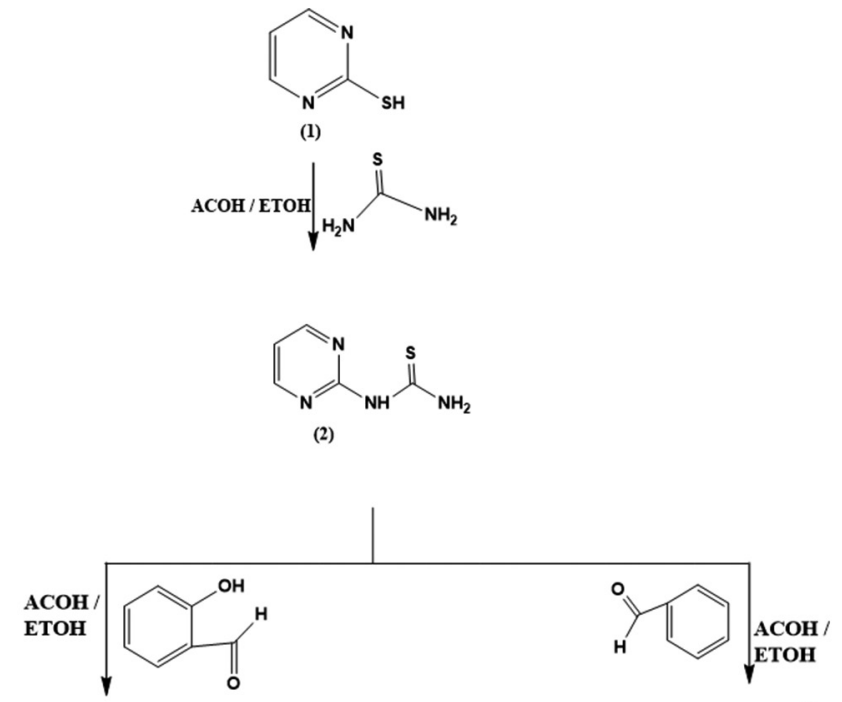

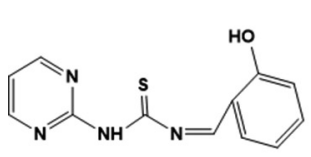

(3)

Scheme 1: Synthesis of some new 2-mercaptopyrimidine Schiff bases

\section{Antifungal screening}

The titled compounds 1-4 were screened for their preliminary antifungal activity using agar disk-diffusion method against pathogenic strains of Aspergillus fumigates, Aspergillus niger, Aspergillus terrus, and Rhizopus. The compounds (1-4) were stored dry at room temperature at concatenation 50 and $100 \mu \mathrm{g} / \mathrm{ml}$. It is prepared in the quality control on feed department/animals resources directorate. The Sabouraud's agar media $\left(15 \mathrm{~cm}^{3}\right)$, kept at $45^{\circ} \mathrm{C}$, were poured into petri dishes, then allowed to solidify. Sterile filter paper discs of $10 \mathrm{~mm}$ diameter were impregnated with prepared derivative $(50 \mu \mathrm{L})$ and placed on to the media, seeded with fungus. The plates were then, incubated at $37^{\circ} \mathrm{C}$ for 1 day. The test compounds were previously dissolved in DMSO, which is used as a control, the zone of inhibition (ZI) was measured in (mm).

\section{Antibacterial screening}

The antimicrobial activities of the synthesized derivatives were measured using well diffusion technique [13], and it was done in the quality control on feed department/animals resources directorate. The synthesized derivatives had been evaluated in vitro against Gram-positive Bacillus subtilis and Staphylococcus aureus, and Gram-negative Klebsiella pneumoniae, Escherichia coli, and Salmonella typhi. DMSO was used as a solvent and control [13-16].

\section{RESULTS AND DISCUSSION}

The first compound (2) was used as the key intermediate, to prepare compounds (3) and (4), through its reaction with 2-hydroxybenzaldehyde and benzaldehyde, respectively. The analytical and physical data are listed in Table 1.

Compound (2) prepared from pyrimidine-2-thiol (1), by its reaction with thiourea, and was used as starting material for the present investigation of the study, due to the presence of ( $\mathrm{SH}$ ) active site, A further proof of compound (2) was achieved through the reaction with a variety of electrophiles, such as carbonyl compounds with the objective of synthesis of the other new derivatives. Thus, compound (2) treated with aromatic aldehydes namely, 2- hydroxyl benzaldehyde, and benzaldehyde in ethanol, containing glacial acetic acid, to give the corresponding compounds (3) and (4), respectively.

\section{Antimicrobial activity}

The antimicrobial activity was evaluated by a filter paper disk agar diffusion method. For antibacterial studies, HiMedia bacteriological nutrient broth, and bacteriological nutrient agar were used against two Gram-positive B. subtilis and S. aureus, and three Gram-negative K. pneumoniae, E. coli, and S. typhi. Antifungal studies were carried out, using Sabouraud's dextrose broth and dextrose agar against $A$. fumigates, A. niger, A.terrus and Rhizopus. The concentrations of the compounds taken were 50 and $100 \mu \mathrm{g} / \mathrm{ml}$. The sensitivity of microorganisms to the compounds is identified in Figs. 1 and 2. Electron-rich nitrogen heterocyclic, play an essential role in diverse biological activities. Introducing pyrimidine derivative rings compounds $(1,2,3$, and 4) influence the antibacterial or pharmacokinetic properties. The antimicrobial activity of compounds (1-4) was tested, and the results are shown in Figs. 1 and 2, and Tables 2 and 3, respectively.

The evaluation of the new compounds (3) and (4) at a concentration of $100 \mu \mathrm{g} / \mathrm{ml}$ have shown the highest inhibitory activity against Grampositive bacteria, $B$. subtilis and $S$. aureus also have displayed the same highest inhibitory activity against the Gram-negative bacteria. The compounds (1) and (2) at a concentration of $100 \mu \mathrm{g} / \mathrm{ml}$ have shown slight inhibitory activity against Gram-positive bacteria $B$. subtilis and S. aureus, while compounds (1) and (2) have shown moderate to potent inhibitory activity against Gram-negative bacteria.

The compound (4) at a concentration of $50 \mu \mathrm{g} / / \mathrm{ml}$ have shown slight inhibitory activity against Gram-positive bacteria B. subtilis and S. Aureus; furthermore, compounds (2) and (3), at a concentration of $50 \mu \mathrm{g} / \mathrm{ml}$ have shown the same slight inhibitory activity against Grampositive bacteria, while compound (1) was not sensitive against Grampositive at a concentration of $50 \mu \mathrm{g} / \mathrm{ml}$. 
Table 1: Physical data of synthesized compounds (1-4)

\begin{tabular}{|c|c|c|c|c|c|}
\hline Compound no. & Chemical formula & Melting point & Physical state & $\mathbf{R}_{f}$ & $\%$ Yield \\
\hline 1 & $\mathrm{C}_{4} \mathrm{H}_{4} \mathrm{~N}_{2} \mathrm{~S}$ & $230^{\circ} \mathrm{C}$ & Deep yellow crystals & 0.9 & - \\
\hline 2 & $\mathrm{C}_{5}^{4} \mathrm{H}_{6}^{4} \mathrm{~N}_{4}^{2} \mathrm{~S}$ & $89^{\circ} \mathrm{C}$ & Pale yellow crystals & 0.66 & 80 \\
\hline 3 & $\mathrm{C}_{12}^{3} \mathrm{H}_{10}^{0} \mathrm{~N}_{4}^{4} \mathrm{OS}$ & $134^{\circ} \mathrm{C}$ & Orange crystals & 0.58 & 70 \\
\hline 4 & $\mathrm{C}_{12}^{12} \mathrm{H}_{10}^{10} \mathrm{~N}_{4}^{4} \mathrm{~S}$ & $165^{\circ} \mathrm{C}$ & Orange crystals & 0.52 & 60 \\
\hline
\end{tabular}

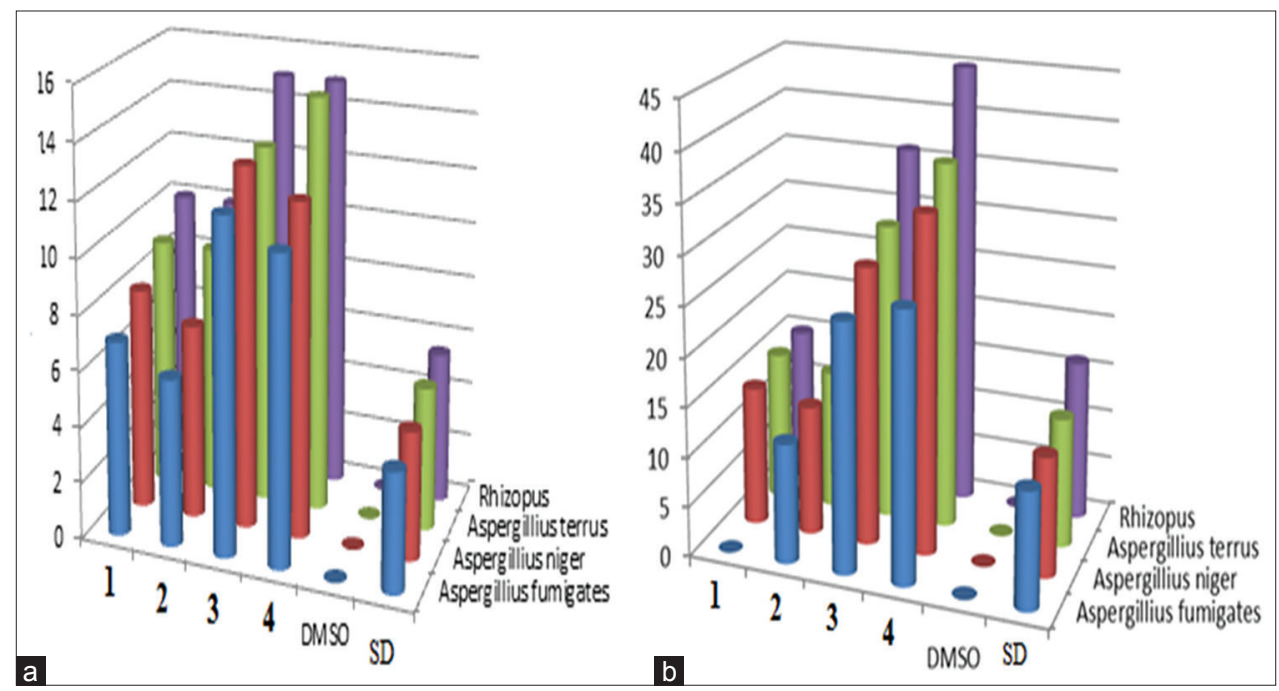

Fig. 1: Antifungal activity of compounds (1-4): (a) Conc. $=50 \mu \mathrm{g} / \mathrm{ml}$; (b) conc. $=100 \mu \mathrm{g} / \mathrm{ml}$

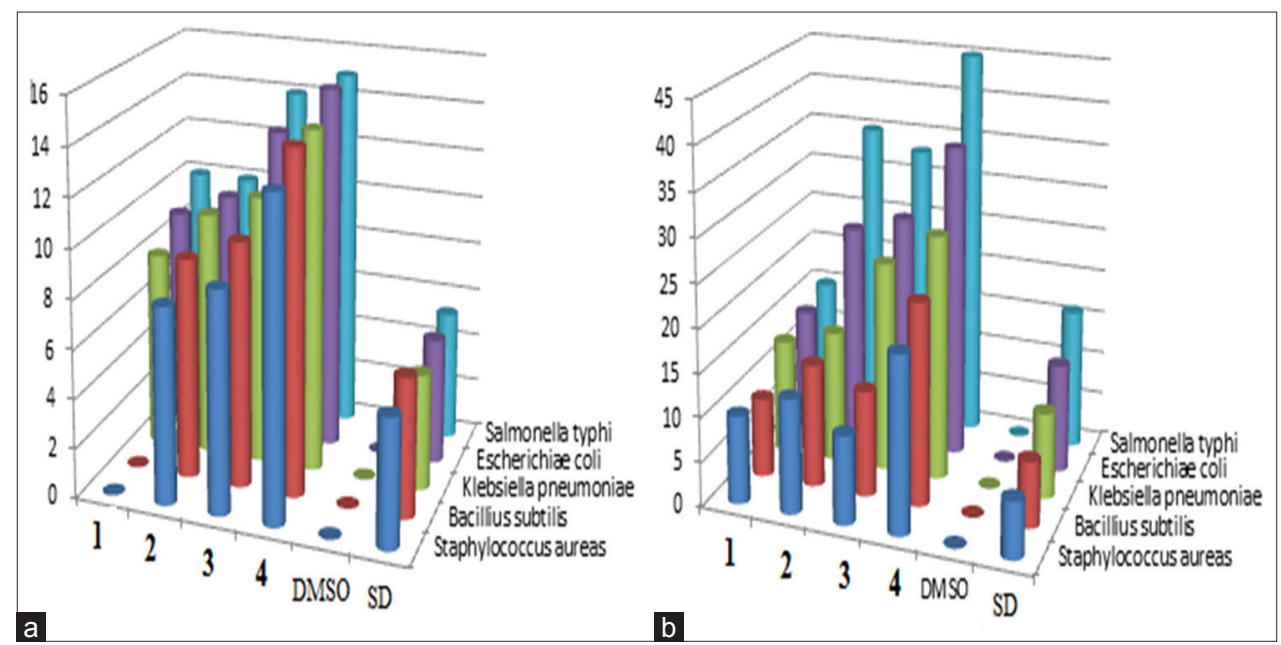

Fig. 2: Antibacterial activity of compounds (1-4): (a) Conc. $=50 \mu \mathrm{g} / \mathrm{ml}$, (b) conc. $=100 \mu \mathrm{g} / \mathrm{ml}$

The compounds (1) and (2) revealed moderate inhibitory activity toward all of the fungi, while compounds (3) and (4) displayed more potent activity against the tested fungi, at a concentration of $100 \mu \mathrm{g} / \mathrm{ml}$ [Fig. 1].

Finally, when the concentration equal to $50 \mu \mathrm{g} / \mathrm{ml}$, the compounds (1) and (2) revealed slight sensitive activity toward all of the fungi, while compounds (3) and (4) were with more moderate activity against the tested fungi (Fig. 1).

\section{Computational studies}

The quantum chemical calculations were validated on the new pyrimidine derivatives using DFT methodology with $3-21 \mathrm{G}^{*}$ basis, while the molecular, atomic charges were approved using the Mulliken population analysis.

The molecular representation sketch of the new pyrimidine compounds was plotted using ChemBioOffice 2010 software [17].

\section{Structural and electronic properties}

DFT calculations were carried out for 2-mercapto pyrimidine compound. The compounds 1, 2, 3, and 4, respectively, with optimized geometries and 3D geometrical structures, are given in (Fig.3).

The determined bond angle and twist angle, stretch, bend, stretch-bend, torsion, and total energy, and the 3D geometrical structure confirmed that compounds (1) and (2) have no stereochemistry, while compound (3), the stereochemistry is: $\mathrm{N}(36)-\mathrm{C}(38)$ is (Z), and compound (4) the stereochemistry is: $\mathrm{N}(9)-\mathrm{C}(11)$ is (Z). The physical parameters are calculated and displayed in Table 4.

\section{Molecular modeling studies}

The HOMO and the LUMO studies have been carried out, using DFT based quantum chemical descriptors. Fig. 4 shows that charge transfer occurs within the molecules and the calculated HOMO and LUMO in electron volt value. The HOMO energies of 2-meracptopyrimidine derivatives 
Table 2: Antifungal activity of the tested compounds

\begin{tabular}{|c|c|c|c|c|c|c|c|c|}
\hline \multirow{3}{*}{$\begin{array}{l}\text { Compound No. } \\
\text { Conc. } \mu \mathrm{g} / \mathrm{ml}\end{array}$} & \multicolumn{8}{|c|}{ Zone of inhibition (mm) } \\
\hline & \multicolumn{2}{|c|}{ Aspergillus fumigates } & \multicolumn{2}{|c|}{ Aspergillus niger } & \multicolumn{2}{|c|}{ Aspergillus terrus } & \multicolumn{2}{|c|}{ Rhizopus } \\
\hline & 100 & 50 & 100 & 50 & 100 & 50 & 100 & 50 \\
\hline 1 & 13 & 7 & 14 & 8 & 15 & 9 & 15 & 10 \\
\hline 2 & 12 & 6 & 13 & 7 & 14 & 9 & 15 & 10 \\
\hline 3 & 25 & 12 & 28 & 13 & 30 & 13 & 36 & 15 \\
\hline 4 & 27 & 11 & 34 & 12 & 37 & 15 & 45 & 15 \\
\hline DMSO & 0 & 0 & 0 & 0 & 0 & 0 & 0 & 0 \\
\hline SD & +9.8 & +4.3 & +12 & +4.6 & +13 & +5.2 & +16.2 & +5.5 \\
\hline
\end{tabular}

Highly sensitive $(>15 \mathrm{~mm})=+++$; moderately sensitive $(10-15 \mathrm{~mm})=++$; slightly sensitive $(5-10 \mathrm{~mm})=+$; and not sensitive $(0 \mathrm{~mm})=-$, SD: Standard deviation, DMSO: Dimethyl sulfoxide

Table 3: Antibacterial activity of the tested compounds (1-4)

\begin{tabular}{|c|c|c|c|c|c|c|c|c|c|c|}
\hline \multirow[t]{3}{*}{ Compound. No. } & \multicolumn{10}{|c|}{ Zone of inhibition (mm) } \\
\hline & \multicolumn{4}{|c|}{ Gram-positive } & \multicolumn{6}{|c|}{ Gram-negative } \\
\hline & \multicolumn{2}{|c|}{ Staphylococcus aureus } & \multicolumn{2}{|c|}{ Bacillus subtilis } & \multicolumn{2}{|c|}{ Klebsiella pneumoniae } & \multicolumn{2}{|c|}{ Escherichia coli } & \multicolumn{2}{|c|}{ Salmonella typhi } \\
\hline Conc. $\mu \mathrm{g} / \mathrm{ml}$ & 100 & 50 & 100 & 50 & 100 & 50 & 100 & 50 & 100 & 50 \\
\hline 1 & 10 & 0 & 9 & 0 & 13 & 8 & 14 & 9 & 15 & 10 \\
\hline 2 & 13 & 8 & 14 & 9 & 15 & 10 & 25 & 10 & 35 & 10 \\
\hline 3 & 10 & 9 & 12 & 10 & 24 & 11 & 27 & 13 & 33 & 14 \\
\hline DMSO & 0 & 0 & 0 & 0 & 0 & 0 & 0 & 0 & 0 & 0 \\
\hline SD & \pm 6.4 & \pm 5.2 & \pm 7.4 & \pm 5.6 & \pm 9.7 & \pm 4.7 & \pm 12.4 & \pm 5.2 & \pm 16 & \pm 5.3 \\
\hline
\end{tabular}

SD: Standard deviation, DMSO: Dimethyl sulfoxide

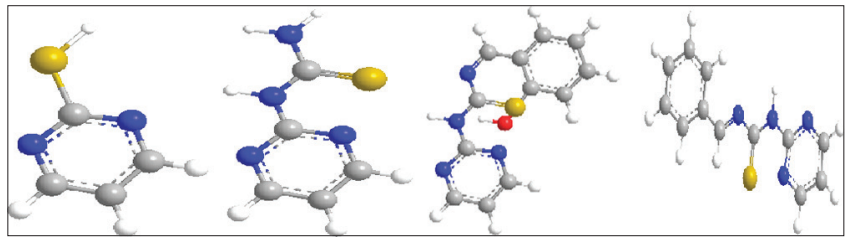

Fig. 3: Optimized 3D geometrical structures for compounds 1, 2, 3 , and 4

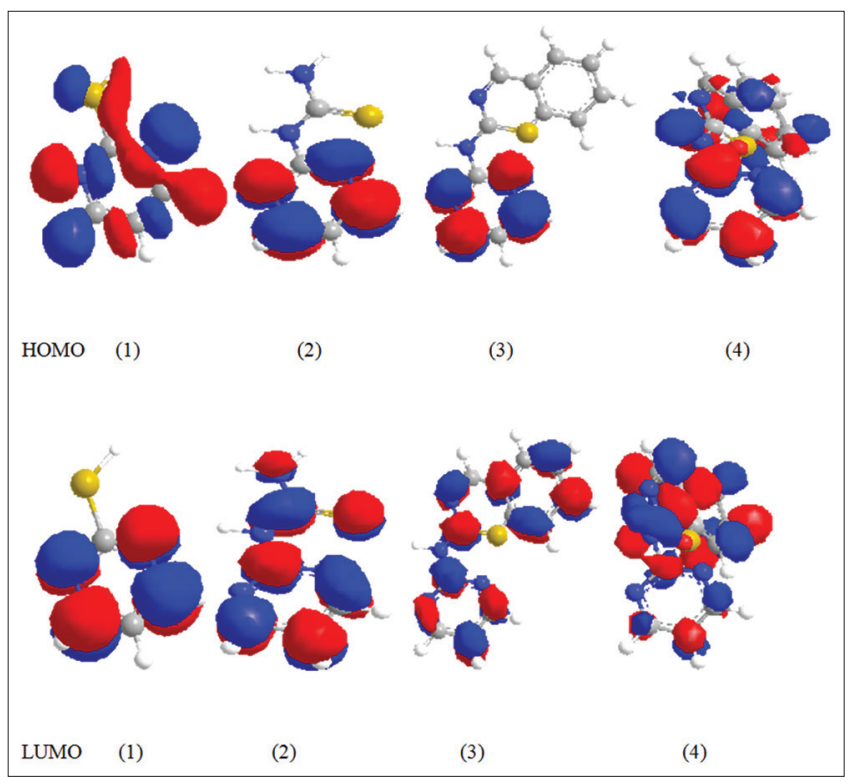

Fig. 4: Highest occupied molecular orbital (HOMO), and the lowest unoccupied molecular orbital (LUMO) for compounds (1-4)

(1-4) are: $-9.53 \mathrm{eV},-0.815 \mathrm{eV}, 3.53 \mathrm{eV}$, and $-0.991 \mathrm{eV}$, respectively, while the LUMO energies of synthetic 2-meracptopyrimidine derivatives
(1-4) are calculated as: $-0.999 \mathrm{eV}, 1.634 \mathrm{eV}, 0.612 \mathrm{eV}$, and $0.411 \mathrm{eV}$, respectively (Table 5).

\section{Global reactivity descriptors and electronic properties}

The energy gap $(8.531 \mathrm{eV}, 2.449 \mathrm{eV}, 2.918 \mathrm{eV}$, and $1.432 \mathrm{eV})$ of synthesized 2-meracptopyrimidine derivatives (1-4) (Table 5). The charge density delocalization over the amide group in the compounds (1-4) detects measurable differences for HOMO and LUMO of 2-mercaptopyrimidine derivatives (1-4). For the band gaps, it was clear that highest band gap is for compound (3), which was $2.918 \mathrm{eV}$, and the next value is for compound (2), $-0.819 \mathrm{eV}$, (Table 5). The charge density, reactivity index, and bond properties of 2-mercaptopyrimidine derivatives (1-4) were calculated depending on the dipole moment. It can be calculated with the help of dipole moment of bonds. The values of dipole moment for 2-mercaptopyrimidine derivatives (1-4) are shown in Table 5. The ionization potential (IP) and electron affinity (EA) can be expressed as the total of energy released when an electron absorbed by a neutral molecule [18] which is approximated as (IP) $=-\mathrm{E}_{\text {номо }}$ and $\mathrm{EA}=-\mathrm{E}_{\mathrm{LUм0}}$, respectively, based on Koopman's theorem [19]. The electrophilicity index has been used as structural chemical hardness $(\eta)$, a chemical potential $(\mu)$, softness descriptor for the analysis of the chemical reactivity of $1 / 2 \eta$, and electrophilicity index $(\omega)$ of a molecule.

A molecule with a lower value of $\mu$, and $\omega$ considered the more reactive nucleophile, while, in the opposite, a molecule with a high value of $\mu$, and $\omega$ recognized as a good electrophile [20]. The electro-negativity and hardness are most commonly used to predict the chemical behavior to clarify aromaticity in the organic compounds [21]. The molecule that has large HOMO-LUMO gap is considered a hard molecule, while a molecule that has small HOMO-LUMO gap, considered a soft molecule. The LUMO represents electron(s) accepting ability, and HOMO as electron donating ability of a molecule [22]. The energy band gap, HOMO, LUMO, dipole moment, softness, chemical potential, nucleophilicity $\mathrm{N}^{\circ}$, power electron-accepting, and electrophilicity index ( $\omega)$, are calculated and displayed in Table 5 .

Molecular docking

In this work, molecular docking investigational study was performed for the synthesized compounds, and Glu-hydroxamate (2-amino- 
Table 4: Physical parameters for compounds 1, 2, 3, and 4 using DFT with 3-21G* basis

\begin{tabular}{lllll}
\hline Parameter & Compound 1 & Compound 2 & Compound 3 & Compound 4 \\
\hline Stretch & 0.1774 & 0.3395 & 1.0776 & 0.7193 \\
Bend & 0.955 & 2.5456 & 14.6172 & 3.5875 \\
Stretch-Bend & 0.0211 & -0.01 & 0.074 & 0.0259 \\
Torsion & 2.0002 & 3.1066 & -3.8034 & -5.7453 \\
Log P & 0.8 & 0.05 & 2.55 & 2.65 \\
Total energy: $\mathrm{kcal} / \mathrm{mol}$ & 8.9552 & 8.1715 & 22.1441 & 9.7626 \\
\hline
\end{tabular}

DFT: Density functional theory

Table 5: Electronic properties of synthesized 2-mercaptopyrimidine derivatives using DFT with 3-21G* basis

\begin{tabular}{|c|c|c|c|c|}
\hline Parameter & Compound 1 & Compound 2 & Compound 3 & Compound 4 \\
\hline Dipole moment (Debye) & 0.2449 & -3.671 & -2.4073 & -3.9809 \\
\hline IP eV & 9.53 & 0.815 & -3.53 & 0.991 \\
\hline $\mathrm{EA} \mathrm{eV}$ & 0.999 & -1.634 & -0.612 & -0.411 \\
\hline Hardness ( $\eta)$ & 4.27 & 1.225 & -1.5775 & 0.716 \\
\hline Softness (S) & 0.117 & -0.408 & -0.317 & 0.698 \\
\hline Electronegativity $(\mu)$ & -10.529 & -3.025 & -0.1215 & -0.58 \\
\hline Electrophilic index $(\omega)$ & 12.98 & 3.73 & -0.0046 & -0.235 \\
\hline $\mathrm{E}_{\text {Lимо }}^{\text {НОмО }} \mathrm{eV}$ & -0.999 & 1.634 & 0.612 & 0.411 \\
\hline Band gap $=\mathrm{E}_{\text {номо }}-\mathrm{E}_{\text {цимо }} \mathrm{eV}$ & -8.531 & -0.819 & 2.918 & -1.402 \\
\hline Energy gap $=\mathrm{E}_{\text {LUмо }}-\mathrm{E}_{\text {номо }} \mathrm{eV}$ & 8.531 & 2.449 & -2.918 & 1.432 \\
\hline Nucleophilicity $\mathrm{N}^{\circ}$ & -9.53 & -0.815 & 3.53 & -0.991 \\
\hline Power electron accepting & 12.98 & 3.73 & -0.0046 & -0.235 \\
\hline
\end{tabular}

IP: Ionization potential, EA: Electron affinity

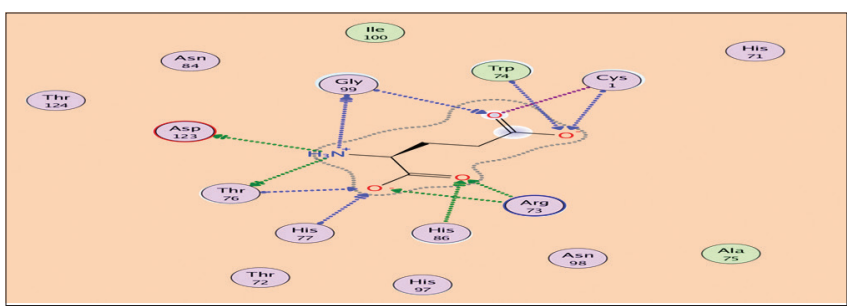

Fig. 5: Binding mode of glutamic acid as a biologically active ligand in glutaminase domain protein crystal, formed eleven hydrogen bonds with Asp123, Arg73, Gly99, Trp74, Cys1, His86, His77, and Thr76 residues

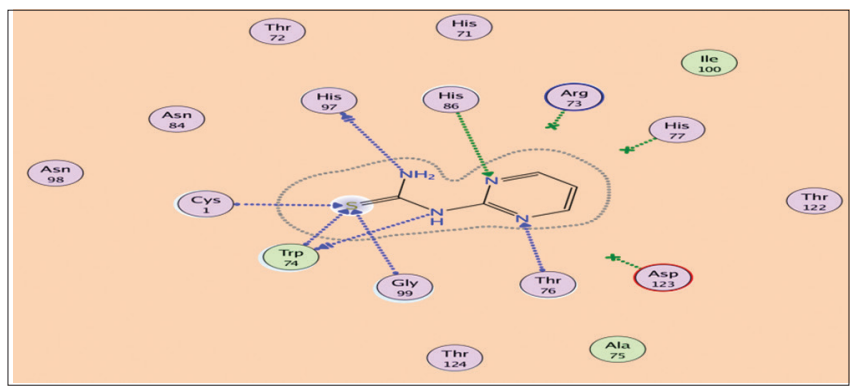

Fig. 6: Binding mode of compound 2 as glutaminase domain active site blocker

5-(hydroxyamino)-5-oxopentanoic acid) used as a competitive reference inhibitor (Figs. 15 and 16) [23]. This study was carried out to gain further insight into the binding modes of the synthesized compounds, into the amino acids in the binding site of glutaminase domain of glucosamine 6-phosphate synthase (ID: 1XFF). The binding free energies (DG) were reported in (Table 6). The free energies, with their negative values, indicate the spontaneity of bindings. The reported key binding site of glutaminase domain of glucosamine 6-phosphate synthase consists of amino acid residues of Asp123, Arg73, Gly99, Trp74, Cys1, His86, His77, and Thr76, (Fig. 5). The

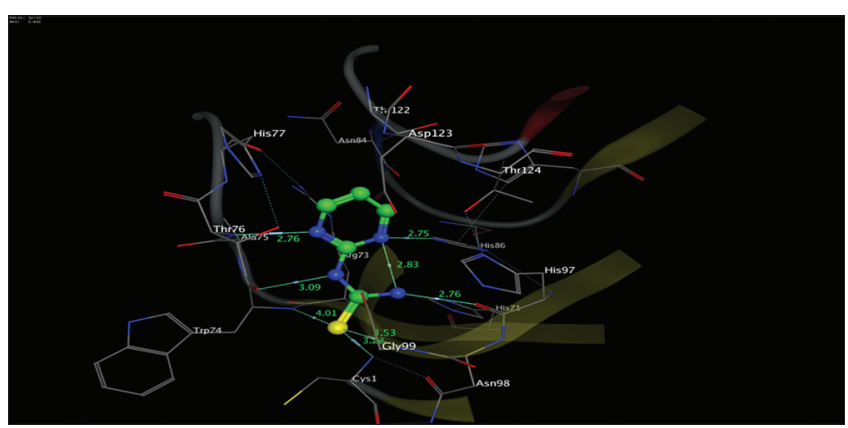

Fig. 7: Compound 2 docked into the active site of glutaminase formed seven hydrogen bonds (green) with Gly99, Trp74, Thr76, and Cys 1 residues

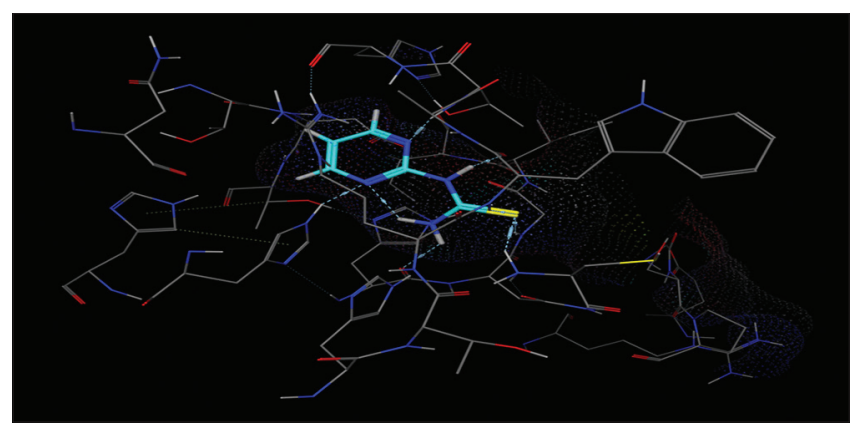

Fig. 8: Mapping surface showing compound 2 occupying the active pocket of glutaminase

proposed binding mode of Glu-hydroxamate showed affinity value equals - $5.78 \mathrm{kcal} / \mathrm{mol}$, with root mean square deviation value of 1.25 [Figs. 15 and 16]. The essential pharmacophoric features atoms formed interactions with the different key residues of Arg73, Gly99, Trp74, Cys1, Thr124, His77, and Thr76. The acidic NH group of amid moiety formed a hydrogen bonding interaction with Thr124. The $\mathrm{C}=\mathrm{O}$ group of amid moiety formed a hydrogen bonding interaction 
Table 6: The table showing (DG), number of bonds and amino acid that bind with pharmacophoric features

\begin{tabular}{lllll}
\hline Compound No. & Binding free energies (DG) kcal/mol & \multicolumn{2}{l}{ Number of bonds } & Amino acids \\
\hline 2 & -5.93 & H.b & $p i$ & Gly99, Trp74, Thr76, Cys1 \\
& & 7 & 0 & Gly99, Trp74, Thr76, Cys1, Arg73 \\
3 & -5.77 & 6 & 2 & Gly99, Trp74, Thr76, Cys1, Asn98, Arg73 \\
4 & -6.11 & 6 & 2 & Gly99, Trp74, Thr76, Cys1, Arg73, His77, Thr124 \\
Glu-hydroxamate & -5.78 & 7 & 0 & \\
\hline
\end{tabular}

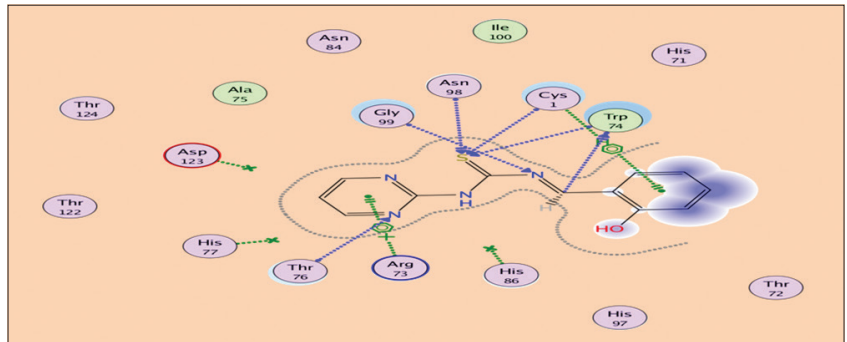

Fig. 9: Binding mode of compound 3 as glutaminase domain active site blocker that is showing good blocking effect by hydrophobic bulky groups

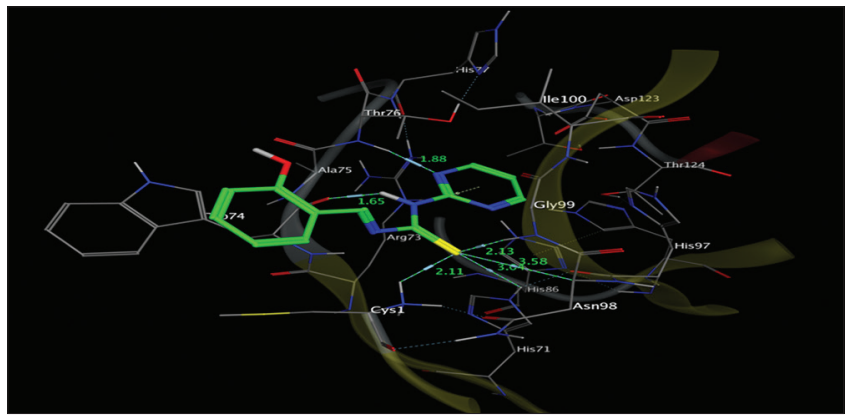

Fig. 10: Compound 3 docked into the active site of glutaminase formed seven hydrogen bonds (green) with Gly99, Trp74, Thr76, and Cys1 residues and pi-pi interactions with Cys1 and Arg73

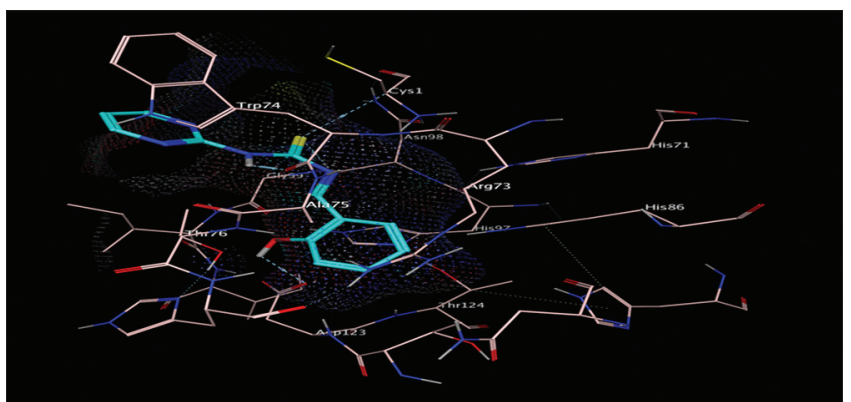

Fig. 11: Mapping surface showing compound 3 occupying the active pocket of glutaminase, hydrophobic moiety, shows good block for free active size in pocket

with Thr76, Arg73, and His77. The basic $\mathrm{NH}_{2}$ group was involved in hydrogen bonding interaction with Gly99. The $(\mathrm{C}=0)$ group of carboxylic moiety formed a hydrogen bond with Cys1 Compounds 3 and 4, Fig.9 and 12 and Trp74 (Fig. 15). The proposed binding mode of compounds (2,3, and 4) showed affinity values, respectively, equal $-5.93,-5.77$, and $-6.11 \mathrm{kcal} / \mathrm{mol}$ with seven hydrogen bonds Gly99, Trp74, Thr76, Cys1, and two pi-pi interactions with Arg73, Compounds 3 and 4,(Fig. 9 and 12). Mapping surface showing compound (2) is occupying the active pocket of a receptor, (Fig. 8), and compounds (3) and (4) have a proper occupying capacity at the active pocket, due to the existence of large hydrophobic moiety that is occupying all empty spaces between amino acids (Figs. 11 and 14).

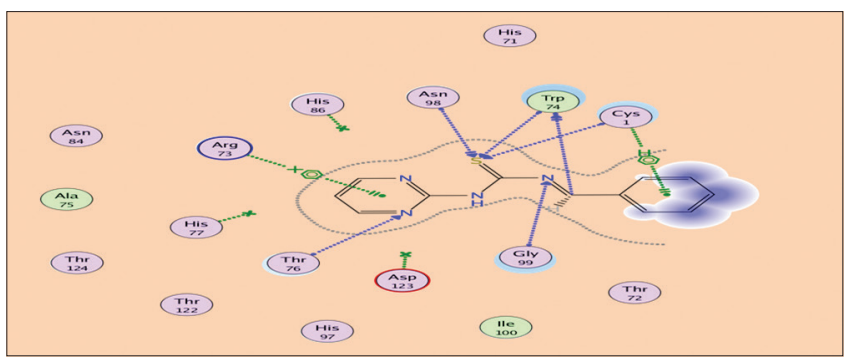

Fig. 12: Binding mode of compound 4 as glutaminase domain active site blocker that is showing good blocking effect by hydrophobic bulky groups

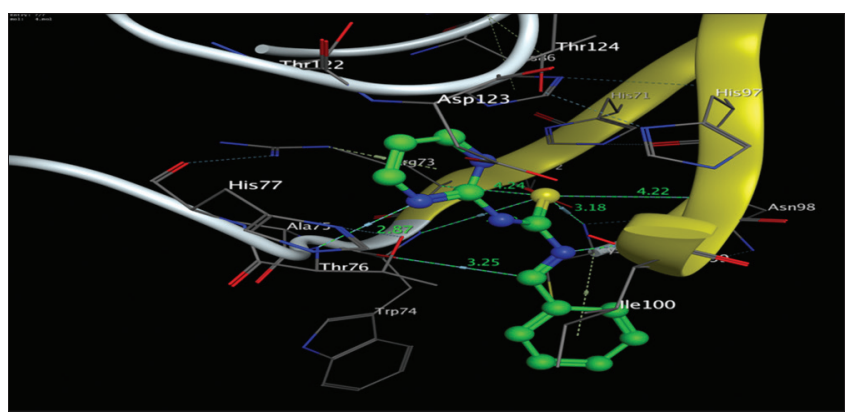

Fig. 13: Compound 4 docked into the active site of glutaminase formed six hydrogen bonds (green) with Gly99, Trp74, Thr76, Cys1, Asn98 residues, and pi-pi interactions with Cys1, and Arg73

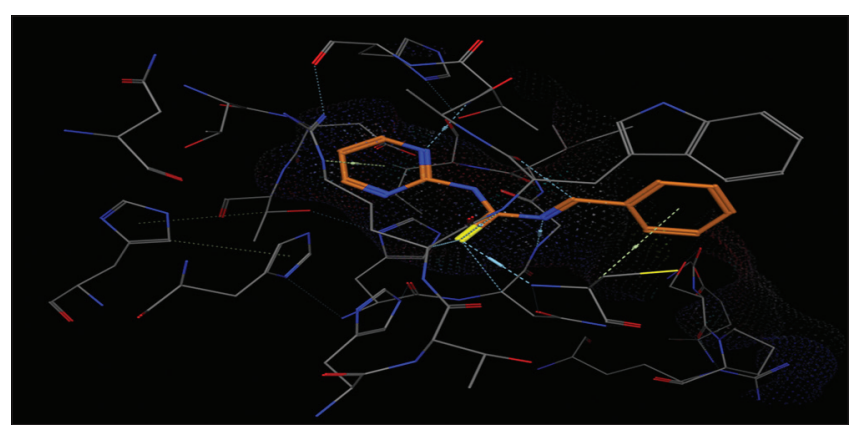

Fig. 14: Mapping surface showing compound 4 occupying the active pocket of glutaminase

\section{CONCLUSION}

In the present work, a series of new pyrimidine derivatives have been synthesized from 2-mercaptopyrimidine by refluxing of thiourea and 2-mercaptopyrimidine, in an acidic medium, the formation of different Schiff bases by the reaction of a compound (2) with different aromatic aldehydes. The titled pyrimidine derivatives were screened in vitro, for their preliminary antibacterial and antifungal activities using 100 and $50 \mu \mathrm{g} / \mathrm{ml}$ concentrations. Schiff bases of 2-mercapto pyrimidine, compounds (3) and (4) showed good antibacterial activity against Grampositive, Gram-negative bacteria, and against fungi used in the evaluation.

Docking results revealed that to design optimal compounds that act as glutaminase domain inhibitor, we must consider the following: 


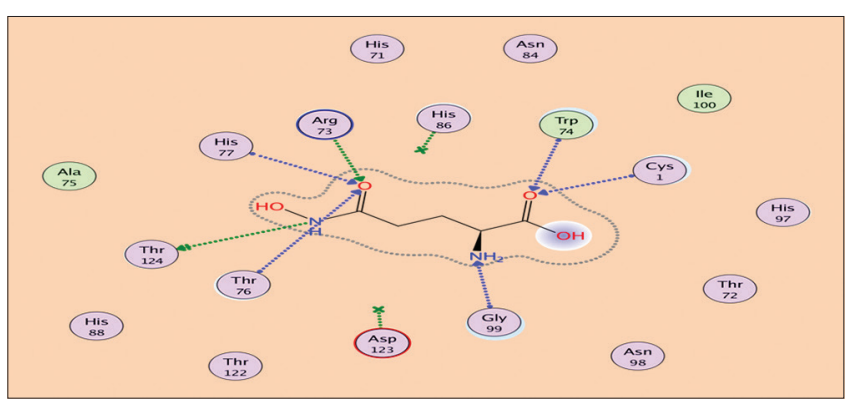

Fig. 15: Binding mode of Glu-hydroxamate as glutaminase domain competitive inhibitor

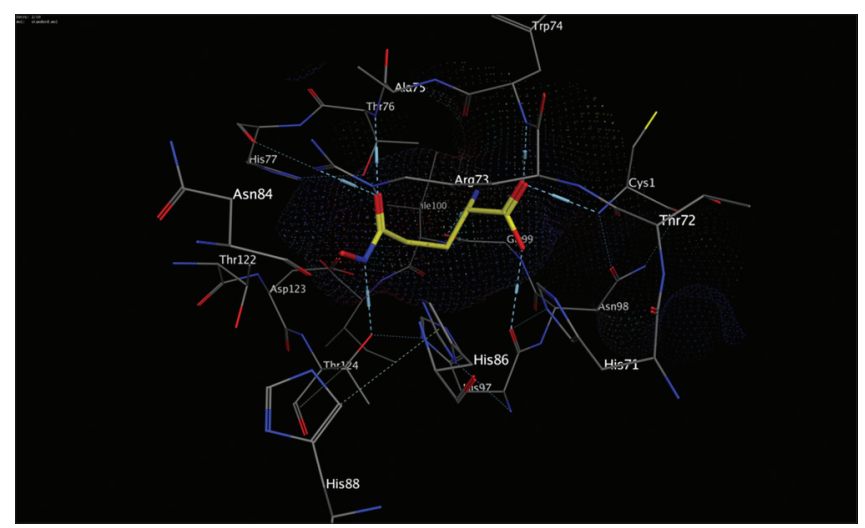

Fig. 16: Mapping surface and Glu-hydroxamate docking into the active site of glutaminase formed seven hydrogen bonds with Gly99, Trp74, Thr76, Cys1, Arg73, His77, and Thr124

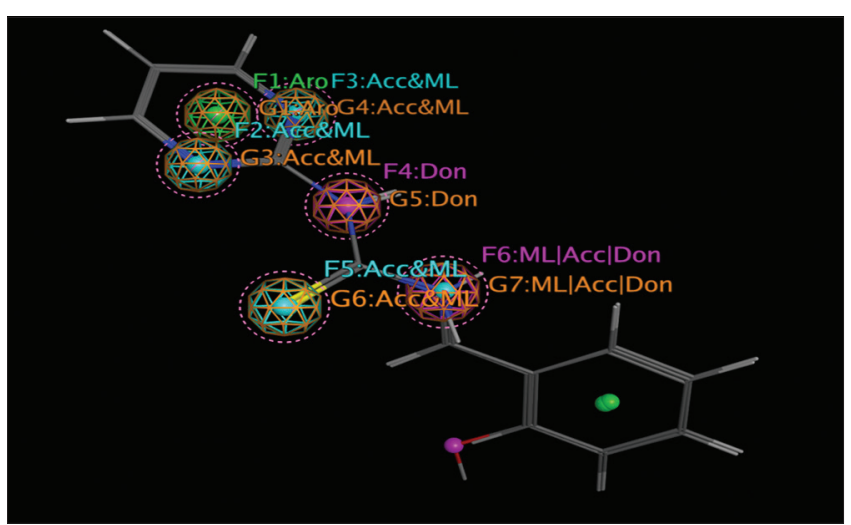

Fig. 17: Image of essential pharmacophoric features of tested compounds that show many centers of hydrogen bonding donors and acceptors

The synthesized compounds should contain many hydrogen bond acceptor and donator centers, to bind with a specific amino acid in the receptor active site (Fig. 17). A convenient choice of a bulky hydrophobic moiety that gives more blocking action on active site as compounds (3) and (4) (Figs. 9 and 12).

\section{ACKNOWLEDGMENT}

The authors are grateful to Dr. Abdulrahman M. Saleh, abdo.saleh240@ gmail.com, Faculty of Pharmacy for boys, Al-Azhar University, Cairo, Egypt, for running docking study and supporting us with the useful data.

\section{AUTHORS' CONTRIBUTIONS}

Both authors contributed equally to writing the manuscript, analyzing the data, read and approved the manuscript.

\section{CONFLICTS OF INTEREST}

All authors have none to declare.

\section{REFERENCES}

1. Stuart AL, Ayisi NK, Tourigny G, Gupta VS. Antiviral activity, antimetabolic activity, and cytotoxicity of 3'-substituted deoxypyrimidine nucleosides. J Pharm Sci 1985;74:246-9.

2. Agarwal A, Ramesh, Ashutosh, Goyal N, Chauhan PM, Gupta S, et al. Dihydropyrido[2,3-d]pyrimidines as a new class of antileishmanial agents. Bioorg Med Chem 2005;13:6678-84.

3. Agarwal A, Srivastava K, Puri SK, Chauhan PM. Synthesis of 4-pyrido6-aryl-2-substituted amino pyrimidines as a new class of antimalarial agents. Bioorg Med Chem 2005;13:6226-32.

4. Rahaman SA, Rajendra Pasad Y, Kumar P, Kumar B. Synthesis and anti-histaminic activity of some novel pyrimidines. Saudi Pharm J 2009; $17: 255-8$.

5. Sushma D, Archana, Sukhjinder S, Munirajam S, Nitin K. Synthesis and biological evaluation of 2-[3-(4-methoxy phenyl)propan -3-one ]-5-(substituted phenyl)-1,3,4-oxadiazoles. Ind J Heterocycl Chem, 2008; 17:265-6

6. Nimavat KS, Popat KH, Joshi H. Synthesis, anticancer, antitubercular and antimicrobial activity of some new pyrimidine derivatives. Ind $\mathrm{J}$ Heterocycl Chem 2003;12:217-20.

7. Karale BK, Gill CH. Synthesis of 3-methyl-4-[(chromon-3 yl) methylene]- 1-phenylpyrazolin-5(4H)-ones and their conversion into 2-thio-5-hydroxy-5H[1] benzopyrano [4,3-d]pyrimidines. Indian J Chem 2002;41B:1957-9.

8. Sharma GV, Reddy VM. Synthesis of 1,2 disubstituted- 4-[(chromon3-yl) methylene]imidazolin-5(4H)-ones as potential pharmacological agents. Indian J Heterocycl Chem 1993;3:111-6.

9. Harshalata D, Dhongade HJ, Kavita C. Pharmacological potentials of pyrimidine derivatives: A review. Asian J Pharm Clin Res 2015;8:171-7.

10. Rana K, Kaur B, Kumar B. Synthesis and antihypertensive activity of some dihydropyrimidines. Indian J Chem B 2004;43:1553-7.

11. Sadagopan S, Nagaraja N, Sridhara AM, Peethamber SK. Synthesis and pharmacological evaluation of certain schiff base of octahydro- $1 \mathrm{H}-$ pyro-[3, 4-B] pyridine derivative. Int J Pharm Pharm Sci 2015;7:412-9.

12. Kumara KS, Kirshnamurthy G, Sunil K. Synthesis, characterization, invitro antimicrobial, anthelmintic and docking studies of new 2-[(E)- $\{[4-$ (1H-1,2,4-traizole-1 ylmethyl)Phenyl]imino methyl]phenol, and their complexes with 3D metal ions. Int J Pharm Pharm Sci 2016;8:134-9.

13. Pfoze NL, Kumar Y, Myrboh B, Bhagobaty RK, Joshi SR. In vitro antibacterial activity of alkaloid extract from stem bark of Mahonia manipurensis. Takeda. J Med Plants Res 2011;5:859-61.

14. Dabholkar VV, Gavande RP. Synthesis and antimicrobial activities of novel 1, 4-benzothiazine derivatives. Arab J Chem 2016;9:S225-9.

15. Ali P, Meshram J, Tiwari V, Dongre R, Sheikh J, Ahemad M. Bis-N-aryl- $\beta$ lactams: Vilsmeier reagent as an efficient entity for the synthesis via alternate cyclo-addition reaction and in vitro biology. Pharm Chem 2010;2:138-47.

16. Ali PS, Meshram JS, Raut RD. Theoretical and synthetic approach towards the biology of some novel monobactam induced sulphonamides: Assessing biology through coupling of active ingredients. Jordan J Chem 2011;6:153-64.

17. Husseein MD, Aljuboori S, Ammar MA. Synthesis, characterization and antibacterial evaluation with computational study of new schiff bases derived from 7-hydroxy-4-methyl coumarin. Orient J Chem 2017;33:768-82.

18. Husseein MD, Ammar MA, Aljuboori S. Synthesis, antibacterial and DFT study of derivatives derived from oxidation 7-hydroxy 4-methyl coumarin. Int J Pharm Sci Rev Res 2017;46:196-206.

19. Naama J, Alwan G, Obayes H, Al-Amiery A, Al-Temimi A, Kadhum A. Curcuminoids as antioxidants and theoretical study of stability of curcumin isomers in gaseous state. Res Chem Intermediates 2013;39:4040-7.

20. Vektariene A, Vektaris G, Svoboda J. A theoretical approach to the nucleophilic behavior of benzofused thieno[3,2-b]furans using DFT and HF based reactivity descriptors. ARKIVOC 2009;7:311-29.

21. Špirtović-Halilović S, Salihović MB, Veljović E, Osmanović A, Trifunović SC, Završnik D. Chemical reactivity and stability predictions of some coumarins by means of DFT calculations. Glas Hem Tehnol Bosne Herceg 2014;43:57-60.

22. Abbas AF, Turki AA, Hameed AJ. Synthesis, characterization and computational study of some new heterocyclic derived from 1-(biphenyl4-yl)-3-(furan-2-yl)prop-2-en-1-one. J Mater Environ Sci 2012;6:1071-8.

23. Kumar S, Lim AM, Ramasamy K, Vasudevan M, Shah SA, Selvaraj M, et al. Synthesis, molecular docking and biological evaluation of bis-pyrimidine schiff base deriv atives. Chem Cent J 2017;11:1-16. 